\title{
Características físico-químicas e sensoriais da carne de cordeiros terminados com dietas contendo cana-de-açúcar ou silagem de milho e dois níveis de concentrado ${ }^{1}$
}

\author{
André Gustavo Leão², Américo Garcia da Silva Sobrinho ${ }^{3}$, Greicy Mitzi Bezerra Moreno², \\ Hirasilva Borba Alves de Souza ${ }^{3}$, Aline Giampietro ${ }^{2}$, Rodrigo César Rossi ${ }^{4}$, Henrique Leal Perez ${ }^{2}$ \\ 1 Pesquisa financiada pela FAPESP. \\ 2 Pós-Graduação em Zootecnia - FCAV/Unesp - Jaboticabal/SP. \\ ${ }^{3}$ FCAV/Unesp - Jaboticabal/SP. \\ 4 Zootecnista.
}

RESUMO - Com o objetivo de avaliar as características físico-químicas e sensoriais da carne de cordeiros terminados em confinamento com dietas contendo cana-de-açúcar ou silagem de milho em duas relações volumoso:concentrado, 60:40 ou 40:60, utilizaram-se 32 cordeiros Ile de France, não-castrados, com $15 \mathrm{~kg}$ de peso corporal. Os animais foram confinados em baias individuais e abatidos aos $32 \mathrm{~kg}$. As dietas e os músculos estudados não influenciaram o pH aos 45 minutos $(6,56)$ e 24 horas $(5,62)$ após o abate nem a capacidade de retenção de água $(58,38 \%)$ e a perda de peso por cocção $(34,04 \%)$. A cor da carne e da gordura subcutânea não diferiu entre as dietas, entretanto a cor da carne variou entre os músculos longissimus lumborum e triceps brachii. A força de cisalhamento $\left(1,85 \mathrm{kgf} / \mathrm{cm}^{2}\right)$ não foi afetada pelas dietas, porém diferiu entre os músculos, com valores de 1,41 e $2,28 \mathrm{kgf} / \mathrm{cm}^{2}$ para o longissimus lumborum e triceps brachii, respectivamente. Nas análises sensoriais do lombo e da paleta, foram obtidas para os cordeiros alimentados com cana-de-açúcar e maior quantidade de concentrado as maiores notas para sabor $(8,07$ e 8,26$)$, textura $(8,53$ e 8,53$)$, preferência $(8,20$ e 8,46$)$ e aceitação $(8,33$ e 8,26), respectivamente. A cana-de-açúcar na alimentação de cordeiros em confinamento manteve a qualidade físicoquímica da carne, podendo ser utilizada nesta fase de produção e, quando associada a maior quantidade de concentrado na dieta, melhora a qualidade sensorial da carne de cordeiros.

Palavras-chave: carne ovina, confinamento, cor da gordura, escatol, músculos, relação volumoso:concentrado

\section{Physic-chemical and sensorial characteristics of meat from lambs finished with diets containing sugar cane or corn silage and two levels of concentrate}

\begin{abstract}
With the objective of evaluating physic-chemical and sensorial characteristics of meat from lambs finished in feedlot with diets containing sugar cane or corn silage at two roughage:concentrate ratios, 60:40 or 40:60, 32 non-castrated Ile de France lambs, with $15 \mathrm{~kg}$ body weight were used. Animals were confined in individual stalls and were slaughtered at $32 \mathrm{~kg}$ body weight. Studied diets and muscles did not affect pH at 45 minutes (6.56) and 24 hours (5.62) after slaughter, water holding capacity $(58.38 \%)$ or cooking losses (34.04\%). Meat color and subcutaneous fat color did not differ between diets, but meat color varied for the muscles longissimus lumborum and triceps brachii. Shear force $\left(1.85 \mathrm{kgf} / \mathrm{cm}^{2}\right)$ was not affected by diets, but it was different between muscles, with values 1.41 and $2.28 \mathrm{kgf} / \mathrm{cm}^{2}$ for the longissimus lumborum and triceps brachii, respectively. At sensorial analysis of ovine loin and shoulder, the lambs fed sugar cane and higher quantity of concentrate had higher scores for flavor (8.07 and 8.26), texture (8.53 and 8.53), preference (8.20 and $8.46)$ and acceptance ( 8.33 and 8.26 ), respectively. In the diet for feedlot lambs, sugar cane maintained the physic-chemical quality of the meat, so it can be used in this production phase. When associated to higher quantity of concentrate in the diet, sugar cane improves the sensorial quality of lamb meat.
\end{abstract}

Key Words: fat color, feedlot, lamb meat, muscles, roughage:concentrate ratio, skatole

\section{Introdução}

A ovinocultura tem grande potencial para se tornar uma atividade economicamente significativa no agronegócio brasileiro, devido ao incremento da demanda da carne ovina. No entanto, a irregularidade de oferta e a baixa qualidade das carcaças comercializadas ainda limitam o consumo dessa carne no Brasil. 
Objetivando sanar essas deficiências, os setores da cadeia têm se mobilizado no sentido de imprimir qualidade ao produto, abatendo animais jovens e com características favoráveis, por meio do uso de raças de corte especializadas e intensificação dos sistemas de produção. No entanto, embora o sistema de confinamento de cordeiros contribua para o abate precoce dos animais, este sistema muitas vezes é inviável, em decorrência dos altos custos com alimentação (Barros, 2004). O uso da cana-de-açúcar na alimentação de ovinos pode reduzir o custo das dietas, entretanto, para melhor atender às exigências nutricionais de cordeiros destinados à produção de carne, recomenda-se o uso de variedades forrageiras, como a IAC 86-2480, associada a concentrados, pois proporcionam maior consumo e desempenho dos ovinos (Torres \& Costa, 2001).

Destaca-se que a relação volumoso:concentrado e o tipo de volumoso das dietas podem influenciar a qualidade da carne ovina. A alimentação mais volumosa gera carnes mais escuras, em função do aumento da mioglobina do músculo (Priolo et al., 2002), e um maior acúmulo de carotenoides na gordura pode torná-la mais amarelada (Prache et al., 2003a). Cordeiros terminados com maior quantidade de concentrado nas dietas apresentam carne mais macia (Ciria \& Asenjo, 2000), uma vez que a alimentação rica em concentrados resulta em carne com maior teor de gordura intramuscular (Leão et al., 2011). Em pesquisa para avaliação de volumosos na terminação de cordeiros, Madruga et al. (2005) notaram que os animais alimentados com palma forrageira tiveram menor teor de gordura na carne e, por isso, apresentaram qualidade sensorial inferior.

Como os trabalhos com cana-de-açúcar para produção de carne ovina são escassos, embora recentes (Moreno et al., 2010; Ribeiro et al., 2010; Leão et al., 2011; Zeola et al., 2011), estudos sobre a influência do seu uso, associado a concentrados, na qualidade da carne ovina são oportunos. Assim, objetivou-se avaliar o efeito da dieta com maior ou menor teor de concentrado, associado à cana-de-açúcar IAC 86-2480 ou silagem de milho, sobre as características físicoquímicas e sensoriais da carne de cordeiros em confinamento.

\section{Material e Métodos}

O experimento foi realizado na Faculdade de Ciências Agrárias e Veterinárias da Universidade Estadual Paulista (FCAV/Unesp), Campus de Jaboticabal, São Paulo, localizada a $21^{\circ} 15^{\prime} 22^{\prime \prime}$ de latitude Sul e $48^{\circ} 18^{\prime} 58^{\prime \prime}$ de latitude Oeste, com altitude de $595 \mathrm{~m}$. A fase de campo foi realizada no Setor de Ovinocultura e as análises laboratoriais no Laboratório de Tecnologia dos Produtos de Origem Animal, pertencentes a esta Instituição Universitária; no Centro de Tecnologia de Carnes e no Centro de Química de Alimentos e Nutrição Aplicada, ambos do Instituto de Tecnologia de Alimentos (ITAL), em Campinas, São Paulo.

Foram utilizados 32 cordeiros Ile de France, nãocastrados, com peso vivo inicial de $15 \pm 0,37 \mathrm{~kg}$. Os animais foram identificados com marcação numérica na região lombar, everminados e receberam suplementação de vitaminas A, D e E. Posteriormente, foram confinados em baias individuais equipadas com comedouros e bebedouros e dispostas em área coberta. Os cordeiros foram distribuídos em quatro tratamentos, constituídos por dietas com duas relações volumoso:concentrado (60:40 e 40:60) e dois volumosos (silagem de milho e cana-de-açúcar).

As dietas foram formuladas para ser isoproteicas e isoenergéticas e calculadas de acordo com as exigências preconizadas pelo NRC (1985) para cordeiros desmamados com ganhos de peso estimados em $300 \mathrm{~g} / \mathrm{dia}$. Durante todo o período experimental, foram coletadas amostras dos ingredientes e das dietas para análise da composição química das mesmas (Tabelas 1 e 2).

A cana-de-açúcar utilizada no experimento foi a IAC 86-2480, variedade desenvolvida pelo Instituto Agronômico de Campinas (IAC) para alimentação animal. A cana-de-açúcar (1으 corte) pertencia ao canavial experimental da FCAV, formado no ano de 2005, e foi colhida em dias alternados, armazenada em área coberta, e picada por meio de picadeira estacionária, imediatamente antes do fornecimento aos animais.

Tabela 1 - Composição química dos ingredientes das dietas experimentais (expressa na matéria seca)

\begin{tabular}{|c|c|c|c|c|}
\hline Nutriente & Silagem de milho & Cana-de-açúcar & Farelo de soja & Milho \\
\hline Matéria seca $(\%)$ & 29,30 & 26,48 & 88,34 & 86,96 \\
\hline Matéria orgânica (\%) & 25,51 & 24,35 & 81,60 & 84,71 \\
\hline Matéria mineral (\%) & 3,79 & 2,13 & 6,74 & 2,25 \\
\hline Proteína bruta (\%) & 8,67 & 2,92 & 49,06 & 8,95 \\
\hline Extrato etéreo $(\%)$ & 3,02 & 0,43 & 1,86 & 3,87 \\
\hline Lignina $(\%)$ & 2,90 & 3,66 & 2,40 & 2,15 \\
\hline Fibra em detergente neutro $(\%)$ & 43,38 & 35,92 & 14,60 & 16,33 \\
\hline Fibra em detergente ácido (\%) & 22,48 & 20,52 & 10,20 & 3,93 \\
\hline Carboidratos totais $(\%)$ & 84,52 & 94,52 & 42,34 & 84,93 \\
\hline Carboidratos não-fibrosos (\%) & 41,14 & 58,60 & 25,84 & 63,32 \\
\hline
\end{tabular}


A silagem de milho foi confeccionada no Setor de Ovinocultura, em silo tipo trincheira com capacidade para 60 t. A variedade de milho utilizada na confecção da silagem foi a Tork, com densidade de 5 sementes $/ \mathrm{m}$ linear, sendo as plantas colhidas aos 110 dias de idade, com grãos no ponto farináceo-duro.

As concentrações dos carotenoides (betacaroteno, luteína e zeaxantina) dos alimentos (Tabela 3) foram determinadas segundo metodologia utilizada por Carvalho et al. (1992). Os carotenoides foram extraídos com acetona e, então, foi feita a partição em éter de petróleo. Após saponificação e lavagem com água, os mesmos foram detectados e quantificados em espectrofotômetro HITACHI U-2000. Para o cálculo da concentração de cada carotenoide, utilizou-se a seguinte fórmula:

Concentração $(\mathrm{mg} / 100 \mathrm{~g})=\underline{\text { absorbância da amostra } \times \text { diluição da amostra }(\text { volume final })}$ peso da amostra $(\mathrm{g}) \times$ absortividade molar do carotenoide
Os animais foram alimentados diariamente às 7:00 e às 17:00. As pesagens foram realizadas semanalmente e, quinzenalmente, avaliou-se o grau de infestação por helmintos por meio da visualização da coloração da mucosa da conjuntiva dos animais (método Famacha ${ }^{\circledR}$ ), de acordo com Molento et al. (2004).

Ao atingir $32 \mathrm{~kg}$ de peso vivo, os cordeiros foram mantidos em jejum de dieta sólida por 16 horas, sendo posteriormente insensibilizados por eletronarcose $(220 \mathrm{~V}$ por $10 \mathrm{~s}$ ), seguida de sangria, pelo seccionamento das veias jugulares e artérias carótidas. Após esfola, evisceração e retirada da cabeça e dos membros, mediram-se em triplicata, nos músculos longissimus lumborum (lombo) e triceps brachii (paleta) (lado esquerdo), o $\mathrm{pH}\left(\mathrm{pH}_{0}-45\right.$ minutos), por meio de peagâmetro digital acoplado a um eletrodo de penetração, e a cor ( cor $_{0}$ - 45 minutos), utilizando colorímetro

Tabela 2 - Composição percentual dos ingredientes e química das dietas experimentais (expressas na matéria seca)

\begin{tabular}{|c|c|c|c|c|}
\hline \multirow[t]{2}{*}{ Composição } & \multicolumn{4}{|c|}{ Dieta $^{a}$} \\
\hline & $60 \% \mathrm{SM}$ & $60 \% \mathrm{CA}$ & $40 \% \mathrm{SM}$ & $40 \% \mathrm{CA}$ \\
\hline \multicolumn{5}{|l|}{ Ingredientes (\%MS) } \\
\hline Cana-de-açúcar & - & 60,00 & - & 40,00 \\
\hline Ureia & 1,00 & 1,00 & 0,20 & 1,00 \\
\hline Milho moído & 19,20 & 9,55 & 34,10 & 32,30 \\
\hline Farelo de soja & 17,40 & 27,65 & 23,30 & 24,30 \\
\hline Fosfato bicálcico & 0,30 & 0,50 & 0,30 & 0,40 \\
\hline Núcleo mineral ${ }^{\mathrm{b}}$ & 0,50 & 0,50 & 0,50 & 0,50 \\
\hline \multicolumn{5}{|l|}{ Nutrientes (na MS) ${ }^{\mathrm{c}}$} \\
\hline Matéria seca (\%) & 53,71 & 52,37 & 65,83 & 64,59 \\
\hline Proteína bruta (\%) & 18,61 & 19,61 & 20,33 & 20,35 \\
\hline Extrato etéreo (\%) & 3,09 & 1,15 & 3,15 & 2,00 \\
\hline Matéria orgânica (\%) & 94,33 & 95,48 & 94,19 & 94,74 \\
\hline Carboidratos totais $(\%)$ & 72,63 & 74,73 & 70,70 & 72,39 \\
\hline Carboidratos não-fibrosos (\%) & 40,16 & 48,58 & 46,58 & 50,58 \\
\hline Energia metabolizável (Mcal/kg) & 3,91 & 3,81 & 3,94 & 3,83 \\
\hline Cálcio $(\%)$ & 0,74 & 0,65 & 0,75 & 0,81 \\
\hline Fósforo $(\%)$ & 0,38 & 0,36 & 0,41 & 0,36 \\
\hline
\end{tabular}

Tabela 3 - Concentração de carotenoides (mg/100 g) dos volumosos e dos concentrados fornecidos aos cordeiros (expressa na matéria seca)

\begin{tabular}{|c|c|c|c|c|c|c|}
\hline \multirow[t]{2}{*}{ Carotenoide } & \multicolumn{2}{|c|}{ Volumoso } & \multicolumn{4}{|c|}{ Concentrado da dieta* } \\
\hline & Silagem de milho & Cana-de-açúcar & $60 \% \mathrm{SM}$ & $60 \% \mathrm{CA}$ & $40 \% \mathrm{SM}$ & $40 \% \mathrm{CA}$ \\
\hline Betacaroteno & 3,32 & 0,40 & 0,47 & 0,27 & 0,55 & 0,49 \\
\hline Luteína & 4,56 & 0,45 & 0,47 & 0,32 & 0,59 & 0,51 \\
\hline Zeaxantina & 3,93 & 0,43 & 0,49 & 0,30 & 0,59 & 0,53 \\
\hline
\end{tabular}

* Concentrado das dietas: $60 \% \mathrm{SM}=60 \%$ silagem de milho $+40 \%$ concentrado; $60 \% \mathrm{CA}=60 \%$ cana-de-açúcar $+40 \%$ concentrado; $40 \% \mathrm{SM}=40 \%$ silagem de milho $+60 \%$ concentrado; e $40 \% \mathrm{CA}=40 \%$ cana-de-açúcar $+60 \%$ concentrado. 
Minolta CR-200, por meio do sistema CIELAB L* (luminosidade), $\mathrm{a}^{*}$ (intensidade de vermelho) e $\mathrm{b}^{*}$ (intensidade de amarelo), calibrado para um padrão branco. A coloração dos músculos foi determinada na parte interna destes, cinco minutos após o corte, para exposição da mioglobina ao oxigênio, de acordo com Cañeque \& Sañudo (2000).

As carcaças foram transferidas para câmara frigorífica a $4{ }^{\circ} \mathrm{C}$, onde permaneceram sob refrigeração por 24 horas e, ao final desse período, mediram-se novamente em triplicata, nos mesmos músculos, o $\mathrm{pH}\left(\mathrm{pH}_{\mathrm{f}}-24\right.$ horas) e a cor ( $\operatorname{cor}_{f}-24$ horas). Para determinação da cor da gordura

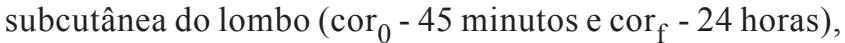
foram utilizados os mesmos equipamentos e procedimentos aplicados na avaliação da carne ovina.

As carcaças foram posteriormente divididas longitudinalmente em duas meias-carcaças. A metade esquerda seccionada em cinco regiões anatômicas: pescoço, paleta, costelas, lombo e perna, conforme descrito por Silva Sobrinho (2001). Os lombos e as paletas foram individualmente identificados, acondicionados em sacos plásticos e armazenados em refrigerador a $-18^{\circ} \mathrm{C}$ até o início das análises. No preparo das amostras para análises, os cortes foram descongelados dentro de sacos plásticos, em geladeira a $10{ }^{\circ} \mathrm{C}$ por 20 horas e dissecados, com auxílio de bisturi e faca, até a obtenção dos músculos longissimus lumborum e triceps brachii, retirando-se da porção medial de cada músculo amostras para determinação da capacidade de retenção de água, perda de peso por coção e força de cisalhamento e análise sensorial.

Na determinação da capacidade de retenção de água, foi utilizada a metodologia descrita por Hamm, citada por Silva Sobrinho (1999), na qual amostras de carne de $500 \pm 20 \mathrm{mg}$ foram colocadas no sentido transversal das fibras sobre papel-filtro entre duas placas acrílicas e sobre estas foi colocado peso de $10 \mathrm{~kg}$ por 5 minutos. Posteriormente, as amostras foram pesadas e, por diferença, calculou-se a quantidade de água perdida. O resultado foi expresso em porcentagem de água exsudada em relação ao peso inicial da amostra.

Para determinação da perda de peso por cocção, as amostras foram pesadas e submetidas a cozimento em forno industrial pré-aquecido a $170{ }^{\circ} \mathrm{C}$, até que a temperatura interna das amostras atingissem $75{ }^{\circ} \mathrm{C}$, quando, então, foram retiradas do forno e pesadas novamente para o cálculo em porcentagem. Na sequência, para determinação da força de cisalhamento, as amostras cozidas foram cortadas em cubos de 1,5 $\mathrm{cm} \times 1,5 \mathrm{~cm}$, para cálculo da área $\mathrm{em}^{2}$, e submetidas ao corte no sentido transversal das fibras musculares, pelo aparelho Texture Analyser, acoplado a lâmina Warner-Bratzler, e os valores foram expressos em $\mathrm{kgf} / \mathrm{cm}^{2}$ (Lyon et al., 1998).

$\mathrm{Na}$ análise sensorial, as amostras dos músculos longissimus lumborum e triceps brachii (in natura) foram salgadas com $1,5 \%$ de sal em relação a seus pesos e assadas em forno pré-aquecido a $170{ }^{\circ} \mathrm{C}$, onde foram mantidas até que a temperatura interna da carne atingisse $75^{\circ} \mathrm{C}$. A partir da carne assada, foram obtidas as amostras, cortadas em cubos paralelamente às fibras musculares (Lyon et al., 1992), e servidas a cada julgador em cabines individuais, em recipientes plásticos codificados com três dígitos aleatórios.

Posteriormente, efetuou-se a degustação por 30 provadores não-treinados utilizando-se escala hedônica de 9 pontos, considerando os atributos sabor (sensação de gosto e odor liberados pela amostra durante a mastigação), textura (percepção da força necessária para obter o cisalhamento da amostra ao morder), preferência e aceitação, atribuindo-se as seguintes notas: 1 - desgostei muitíssimo; 2 - desgostei muito; 3 - desgostei regularmente; 4 - desgostei ligeiramente; 5 -indiferente; 6 - gostei ligeiramente; 7 -gostei regularmente; 8 - gostei muito; e 9 - gostei muitíssimo. Os testes foram aplicados em cabines individuais, com luz vermelha para evitar possíveis influências na aparência das amostras.

Da gordura subcutânea dos lombos, foram retiradas amostras para determinação do composto volátil 3metilindole (escatol). Essas amostras foram embaladas a vácuo para reduzir a volatinização deste composto e analisadas segundo metodologia utilizada por GarciaRegueiro \& Diaz (1989).

O delineamento experimental utilizado nas análises físico-químicas da carne foi o inteiramente casualizado em parcelas subdivididas, tendo nas parcelas um esquema fatorial $2 \times 2$ (duas relações volumoso:concentrado e dois volumosos), e nas subparcelas os músculos avaliados (longissimus lumborum e triceps brachii), com quatro tratamentos e oito repetições. Para análise da cor e concentração de escatol da gordura, utilizou-se o delineamento experimental inteiramente casualizado em esquema fatorial $2 \times 2$ (duas relações volumoso: concentrado e dois volumosos), também com quatro tratamentos e oito repetições. Os dados foram submetidos à análise de variância pelo procedimento GLM do pacote estatístico SAS (SAS, 1996) a 5\% de significância. Quando detectadas diferenças significativas entre os tratamentos para as variáveis em estudo, as mesmas foram comparadas pelo teste de Tukey ao mesmo nível de significância. Para análise estatística das características sensoriais da carne de cordeiros, por tratar-se de escores de avaliação, utilizou-se o Teste Não-Paramétrico de Wilcoxon. 


\section{Resultados e Discussão}

Não houve efeito $(\mathrm{P}>0,05)$ das interações volumoso $\times$ relação volumoso:concentrado; volumoso $\times$ músculo; relação volumoso:concentrado $\times$ músculo; e volumoso $\times$ relação volumoso:concentrado $\times$ músculo; para pH e cor da carne de cordeiros terminados em confinamento. Os volumosos, a relação volumoso:concentrado e o tipo de músculo estudado não influenciaram $(\mathrm{P}>0,05)$ o $\mathrm{pH}$ aos 45 minutos e 24 horas após o abate (Tabela 4 ). No entanto, o declínio do $\mathrm{pH}$ observado nos diferentes músculos 24 horas após o abate evidencia o processo de rigor mortis (Murray, 1995; Silva Sobrinho, 2005).

Esses valores estão dentro da faixa considerada normal para a carne ovina, que, segundo Sañudo et al. (1992), varia de 6,56 a 6,69 para $\mathrm{pH}_{45 \text { min }}$, e de 5,66 a 5,78 para $\mathrm{pH}_{24 \mathrm{~h}}$, e indica a inexistência de estresse pré-abate, uma vez que a pouca susceptibilidade ao estresse pela espécie ovina acarreta queda do $\mathrm{pH}$ dentro dos valores normais (Devine et al., 1993). É importante ressaltar que a constatação de valores normais de queda do $\mathrm{pH}$ sugere que outros parâmetros indicadores da qualidade da carne, como capacidade de retenção de água, cor e maciez, apresentarão bons resultados, pois estes são influenciados pelo $\mathrm{pH}$.

Os valores encontrados para cada tipo de músculo foram semelhantes aos constatados por Oliveira et al. (2004), que estudaram os músculos longissimus dorsi e triceps brachii de cordeiros da raça Santa Inês e também não verificaram diferenças $(\mathrm{P}>0,05)$ entre os mesmos para $\mathrm{pH}$ inicial e final, sendo, respectivamente, 6,67 e 5,61 no músculo longissimus dorsi, e 6,73 e 5,68 no triceps brachii. Sabe-se que o tipo de fibra muscular dominante influencia no $\mathrm{pH}$ final, já que tem relação inversa com o conteúdo de glicogênio acumulado no músculo, ou seja, quanto maior o teor de glicogênio, mais baixo o pH muscular. Músculos ricos em fibras vermelhas (SO) de contração lenta possuem baixa concentração de glicogênio e metabolismo oxidativo, com pouca produção de ácido lático, resultando $\mathrm{em} \mathrm{pH}$ final mais elevado, normalmente acima de 6,3. As fibras musculares intermediárias (FOG) de contração rápida e metabolismo oxidativo-glicolítico possuem alto conteúdo de glicogênio, assim como as fibras brancas (FG) de contração rápida e metabolismo glicolítico, com degradação ativa de glicogênio a ácido lático, resultando em $\mathrm{pH}$ final baixo, normalmente de 5,5 (Garrido \& Bañón, 2000; Cezar \& Sousa, 2007). Neste sentido, pode-se dizer que neste estudo, os valores de $\mathrm{pH}$ final foram semelhantes entre os músculos avaliados (longissimus lumborum e triceps brachii), pois ambos tiveram maior frequência das fibras intermediárias $(73,95 \mathrm{e}$ $53,70 \%$, respectivamente), caracterizando-se como músculos de contração rápida e metabolismo oxidativo-glicolítico (Leão, 2008).

Alguns autores avaliaram o efeito da relação volumoso:concentrado sobre a qualidade da carne de cordeiros Morada Nova (Zeola et al., 2002) e cabritos Saanen (Madruga et al., 2008) e não verificaram diferenças nos valores de pH. Fernandes et al. (2008) analisaram as características da carne de bovinos terminados em confinamento com dietas contendo silagem de milho ou cana-de-açúcar como volumosos e também observaram que o pH da carne não foi influenciado pelas dietas. Já Priolo et al. (2002) e Perlo et al. (2008) relataram que o valor de pH final da carne de cordeiros terminados em pasto é maior que o daqueles confinados, provavelmente em função da atividade física prévia ao abate.

Todas estas respostas confirmam o relato de que o nível de glicogênio muscular tem maior importância sobre o pH e que a dieta ou a natureza do alimento são menos

Tabela 4 - Medidas de pH e cor dos músculos longissimus lumborum (LL) e triceps brachii (TB) de cordeiros terminados em confinamento com dietas contendo silagem de milho (SM) ou cana-de-açúcar (CA) e dois níveis de concentrado

\begin{tabular}{|c|c|c|c|c|c|c|c|}
\hline \multirow[t]{2}{*}{ Variável } & \multicolumn{2}{|c|}{ Volumoso } & \multicolumn{2}{|c|}{ Relação volumoso:concentrado } & \multicolumn{2}{|c|}{ Músculo } & \multirow[t]{2}{*}{$\mathrm{CV}(\%)$} \\
\hline & SM & $\mathrm{CA}$ & $60: 40$ & $40: 60$ & LL & TB & \\
\hline $\mathrm{pH}$ (45 minutos) & 6,54 & 6,58 & 6,57 & 6,55 & 6,61 & 6,50 & 3,17 \\
\hline pH (24 horas) & 5,64 & 5,60 & 5,63 & 5,61 & 5,58 & 5,65 & 2,28 \\
\hline \multicolumn{8}{|l|}{ Cor (45 minutos) } \\
\hline $\mathrm{L}^{*}$ & 35,79 & 35,72 & 35,82 & 35,68 & $34,64 b$ & $36,86 \mathrm{a}$ & 1,93 \\
\hline$a^{*}$ & 12,74 & 12,77 & 12,80 & 12,71 & $13,54 \mathrm{a}$ & $11,97 \mathrm{~b}$ & 4,48 \\
\hline$b^{*}$ & 2,13 & 2,10 & 2,15 & 2,08 & $2,40 \mathrm{a}$ & $1,82 b$ & 10,27 \\
\hline \multicolumn{8}{|l|}{ Cor (24 horas) } \\
\hline $\mathrm{L}^{*}$ & 45,73 & 45,63 & 45,75 & 45,61 & $43,62 b$ & $47,74 \mathrm{a}$ & 1,94 \\
\hline$a^{*}$ & 15,19 & 15,15 & 15,19 & 15,15 & $16,12 \mathrm{a}$ & $14,21 \mathrm{~b}$ & 3,29 \\
\hline $\mathrm{b}^{*}$ & 4,98 & 4,87 & 4,98 & 4,87 & $5,36 \mathrm{a}$ & $4,49 \mathrm{~b}$ & 11,67 \\
\hline
\end{tabular}

Médias seguidas de letras distintas na linha diferem $(\mathrm{P}<0,05)$ entre si pelo teste Tukey.

$\mathrm{CV}=$ coeficiente de variação.

$\mathrm{L}^{*}=$ luminosidade $\mathrm{a}^{*}=$ teor de vermelho e $\mathrm{b}^{*}=$ teor de amarelo. 
importantes (Sañudo, 1991). Entre os fatores alimentares comentados, pode-se inferir que o sistema de produção (pasto ou confinamento) parece ter maior influência sobre o $\mathrm{pH}$ de ruminantes que as dietas propriamente ditas (com maior ou menor teor de concentrado; ou com diferentes volumosos).

Com relação à cor, nota-se que, independentemente do tipo de volumosos e da relação volumoso:concentrado, os valores de $\mathrm{L}^{*}$, a* e b* aos 45 minutos e 24 horas após o abate não diferiram $(\mathrm{P}>0,05)$, com valores médios de 35,75 para $\mathrm{L}^{*}$, 12,76 para a* e 2,12 para b* aos 45 minutos e de 45,68 para $L^{*}, 15,17$ para a* e 4,93 para $b^{*}$ às 24 horas.

Em experimento com diferentes relações volumoso:concentrado para cordeiros Morada Nova em confinamento, Zeola et al. (2002) também constataram que as dietas não afetaram a cor da carne 24 horas pós-abate, com médias de 40,46 para L*; 14,62 para a* e 1,10 para b*, obtidas no músculo semimembranosus. Arquimède et al. (2008) estudaram o efeito da inclusão de níveis crescentes de concentrado $(0,150,300$ e $600 \mathrm{~g})$ nas dietas de cordeiros em confinamento e também verificaram no músculo longissimus lumborum 24 horas pós-abate que as dietas não influenciaram a cor da carne, com médias de 44,38 para $L^{*}, 19,25$ para a* e 6,60 para b*. Fernandes et al. (2008) analisaram as características da carne de bovinos terminados em confinamento com dietas contendo silagem de milho ou cana-de-açúcar como volumosos e observaram que a cor da carne não foi influenciada $(\mathrm{P}>0,05)$ pelas mesmas, com valores de 37,98 e 37,40 para L* 15,86 e 15,32 para a* e 3,20 e 2,64 para b*, respectivamente. Entretanto, Priolo et al. (2002), Díaz et al. (2002) e Perlo et al. (2008), trabalhando respectivamente com cordeiros Ile de France, Talaverana e Corriedale, verificaram que a carne dos animais criados em pasto foi mais escura que a dos confinados, devido ao maior valor de a* (teor de vermelho).
Considerando que, nas pesquisas supracitadas, a coloração mais escura da carne dos animais a pasto esteve relacionada ao aumento da mioglobina do músculo (Priolo et al., 2002), justificado pela maior atividade física desses animais (Perlo et al., 2008), pode-se dizer que provavelmente não houve diferença na cor da carne ovina, uma vez que os cordeiros foram mantidos em confinamento. Assim, pode-se inferir que o sistema de produção (pasto ou confinamento) parece ter maior influência sobre a cor da carne ovina que as dietas (com maior ou menor teor de concentrado; ou com diferentes volumosos), assim como comentado sobre o $\mathrm{pH}$.

Quanto ao tipo de músculo analisado, houve diferença $(\mathrm{P}<0,05)$ para os valores de $\mathrm{L}^{*}, \mathrm{a}^{*} \mathrm{e} \mathrm{b}^{*}$ entre os músculos longissimus lumborum e triceps brachii. Tanto aos 45 minutos quanto às 24 horas, verificaram-se no músculo longissimus lumborum menores valores de $\mathrm{L}^{*}$ e maiores de $\mathrm{a}^{*}$ e $\mathrm{b}^{*}$. O músculo longissimus lumborum apresentou maior valor de a*, ou seja, coloração mais avermelhada que a do triceps brachii, uma vez que, no longissimus lumborum foi verificada maior frequência das fibras oxidativas e oxidativas-glicolíticas (Leão, 2008), que possuem maior teor de mioglobina (Ramos \& Gomide, 2007). Os valores da cor às 24 horas são próximos dos reportados por TschirhartHoelscher et al. (2006), que, em estudo das características físico-químicas de 18 músculos de cordeiros, verificaram no músculo longissimus lumborum os valores de 42,7; 14,7 e 3,8 para as coordenadas $\mathrm{L}^{*}, \mathrm{a}^{*} \mathrm{e}$ b* e no músculo triceps brachii, valores de 43,$5 ; 15,7$; e 3,5, respectivamente. E frente aos valores descritos nos diversos trabalhos citados, os valores obtidos deste experimento foram considerados normais para cor de carne ovina.

Para a cor da gordura subcutânea, não houve efeito $(\mathrm{P}>0,05)$ da interação volumoso $\times$ relação volumoso:concentrado (Tabela 5). Os volumosos e as relações volumoso:concentrado não influenciaram $(\mathrm{P}>0,05)$

Tabela 5 - Medidas de cor da gordura subcutânea do músculo longissimus lumborum de cordeiros terminados em confinamento com dietas contendo silagem de milho (SM) ou cana-de-açúcar (CA) e dois níveis de concentrado

\begin{tabular}{|c|c|c|c|c|c|}
\hline \multirow[t]{2}{*}{ Variável } & \multicolumn{2}{|c|}{ Volumoso } & \multicolumn{2}{|c|}{ Relação volumoso:concentrado } & \multirow[t]{2}{*}{$\mathrm{CV}(\%)$} \\
\hline & SM & $\mathrm{CA}$ & $60: 40$ & $40: 60$ & \\
\hline \multicolumn{6}{|c|}{ Cor (45 minutos) } \\
\hline$a^{*}$ & 4,49 & 4,55 & 4,47 & 4,58 & 4,84 \\
\hline$b^{*}$ & 5,56 & 5,34 & 5,59 & 5,31 & 4,42 \\
\hline \multicolumn{6}{|c|}{ Cor (24 horas) } \\
\hline $\mathrm{b}^{*}$ & 5,81 & 5,56 & 5,87 & 5,50 & 9,67 \\
\hline
\end{tabular}

Médias seguidas de letras distintas na linha diferem $(\mathrm{P}<0,05)$ entre si pelo teste Tukey.

$\mathrm{CV}=$ coeficiente de variação

$\mathrm{L}^{*}=$ luminosidade; $\mathrm{a}^{*}=$ teor de vermelho e $\mathrm{b}^{*}=$ teor de amarelo. 
os valores das coordenadas $\mathrm{L}^{*}, \mathrm{a}^{*} \mathrm{e} \mathrm{b}^{*}$ aos 45 minutos e 24 horas após o abate.

Fernandes et al. (2009), avaliando as características qualitativas da carne de tourinhos terminados em confinamento alimentados com dietas contendo canade-açúcar (var. SP 80-1816) e dois teores de concentrado (40 ou $60 \%$ ), também não verificaram efeito da relação volumoso:concentrado sobre a cor da gordura. Fernandes et al. (2008), no entanto, ao analisarem as características da carne de bovinos terminados em confinamento com dietas contendo cana-de-açúcar ou silagem de milho como volumoso, observaram que os animais que receberam dieta contendo cana-de-açúcar tiveram gordura mais amarela $\left(b^{*}=8,47\right)$ que a dos alimentados com silagem de milho $\left(b^{*}=7,20\right)$. Em pesquisa sobre o efeito dos sistemas de produção sobre a qualidade da carne ovina, Priolo et al. (2002) e Díaz et al. (2002) trabalharam, respectivamente, com cordeiros Ile de France e Talaverana e verificaram que as dietas afetaram $(\mathrm{P}<0,05)$ os valores de $\mathrm{L}^{*} \mathrm{e} \mathrm{b}^{*}$, sendo a gordura dos animais criados em pasto mais brilhante $\mathrm{e}$ amarela que a dos confinados.

Importante salientar que a coloração amarela da gordura está relacionada ao acúmulo de carotenoides - a luteína é o único armazenado no tecido adiposo de ovinos (Yang et al., 1992; Prache et al., 2003a) - e que cordeiros criados a pasto apresentaram 5,5 vezes mais carotenoides no sangue e 3,25 vezes mais luteína na gordura perirrenal em comparação aos criados em confinamento (Prache \& Theriez, 1999; Prache et al., 2003a,b).

Assim, pode-se dizer que o valor de $b^{*}$ verificado neste estudo não foi afetado pelas dietas, provavelmente devido à baixa concentração de luteína presente tanto nos volumosos quanto nos concentrados (Tabela 3). Segundo Knight et al. (1996), as dietas com baixo teor de carotenoides, como grãos, feno e silagem, propiciam redução da cor amarela da gordura de bovinos, em função da diluição da cor da gordura. Prache et al. (2003a) reportaram ainda que a intensidade da absorção de luz pelo carotenoide armazenado na gordura de cordeiros em confinamento foi negativamente correlacionada ao período de confinamento, comprovando que este efeito é mediado pela diluição da gordura de coloração branca (Prache et al., 2003b).

Não houve efeito $(\mathrm{P}>0,05)$ das interações volumoso $\times$ relação volumoso:concentrado, volumoso $\times$ músculo, relação volumoso:concentrado $\times$ músculo e volumoso $\times$ relação volumoso:concentrado x músculo sobre a capacidade de retenção de água, perda de peso por cocção e força de cisalhamento, nem efeito isolado $(\mathrm{P}>0,05)$ dos volumosos, relação volumoso:concentrado e do tipo de músculo sobre a capacidade de retenção de água e perda de peso por cocção desta carne (Tabela 6).

Nota-se que o valor médio encontrado para capacidade de retenção de água $(58,38 \%$ ) foi próximo ao de $59,50 \%$ verificado por Sen et al. (2004) na carne de ovinos criados em condições semiárida recebendo dieta com relação volumoso:concentrado 50:50 e superior aos 52,81\% obtido por Zeola et al. (2002) no músculo semimembranosus de cordeiros Morada Nova alimentados com 30, 45 ou $60 \%$ de concentrado. Contudo, a semelhança dos valores verificados neste estudo corrobora relatos de Sañudo (1991) de que o sistema de produção e a alimentação não afetam a capacidade de retenção de água em ovinos.

A perda de peso por cocção da carne dos cordeiros deste trabalho $(34,04 \%)$ foi inferior aos $37,63 \%$ obtidos por Zeola et al. (2002) no músculo semimembranosus de cordeiros Morada Nova e aos 38,10\% encontrados por Yamamoto (2006) no músculo longissimus lumborum de cordeiros 7/8 Ile de France 1/8 Ideal terminados em confinamento com dietas contendo $40 \%$ de silagem de milho e $60 \%$ de concentrado, com ou sem inclusão de $8 \%$ de silagens de resíduos de peixes.

A força de cisalhamento não foi afetada pelas dietas ( $\mathrm{P}>0,05)$, com média de $1,85 \mathrm{kgf} / \mathrm{cm}^{2}$, entretanto, houve efeito $(\mathrm{P}<0,05)$ dos músculos. Pelos resultados obtidos, pode-se dizer que a carne desses cordeiros é macia, uma vez que, segundo Cezar \& Sousa (2007), carnes ovinas que apresentam valores de força de cisalhamento inferiores a $2,27 \mathrm{kgf} / \mathrm{cm}^{2}$, de 2,28 a $3,63 \mathrm{kgf} / \mathrm{cm}^{2}$, de 3,64 a $5,44 \mathrm{kgf} / \mathrm{cm}^{2}$

Tabela 6 - Capacidade de retenção de água (CRA), perda de peso por cocção (PPC) e força de cisalhamento (FC) dos músculos longissimus lumborum (LL) e triceps brachii (TB) de cordeiros terminados em confinamento com dietas contendo silagem de milho (SM) ou cana-de-açúcar (CA) e dois níveis de concentrado

\begin{tabular}{|c|c|c|c|c|c|c|c|}
\hline \multirow[t]{2}{*}{ Variável } & \multicolumn{2}{|c|}{ Volumoso } & \multicolumn{2}{|c|}{ Relação volumoso:concentrado } & \multicolumn{2}{|c|}{ Músculo } & \multirow[t]{2}{*}{$\mathrm{CV}(\%)$} \\
\hline & SM & $\mathrm{CA}$ & $60: 40$ & $40: 60$ & LL & TB & \\
\hline CRA (\%) & 58,94 & 57,82 & 58,34 & 58,42 & 59,04 & 57,72 & 5,59 \\
\hline $\mathrm{FC}\left(\mathrm{kgf} / \mathrm{cm}^{2}\right)$ & 1,92 & 1,77 & 2,00 & 1,69 & $1,41 \mathrm{~b}$ & $2,28 \mathrm{a}$ & 22,31 \\
\hline
\end{tabular}

Médias seguidas de letras distintas na linha diferem $(\mathrm{P}<0,05)$ entre si pelo teste Tukey.

$\mathrm{CV}=$ coeficiente de variação. 
e, acima de 5,44, podem ser classificadas como macia, de maciez mediana, dura e extremamente dura, respectivamente.

Considerando que os cordeiros terminados com maior quantidade de concentrado nas dietas apresentam carne mais macia (Ciria \& Asenjo, 2000), pelo fato de que a alimentação rica em concentrados imprime maior teor de gordura intramuscular, e que nesta pesquisa a carne dos cordeiros que receberam dietas contendo $60 \%$ de concentrado apresentou maior teor de gordura (Leão et al., 2011), esperava-se efeito das dietas avaliadas.

Já a diferença observada na força de cisalhamento dos músculos longissimus lumborum $\left(1,41 \mathrm{kgf} / \mathrm{cm}^{2}\right)$ e triceps brachii $\left(2,28 \mathrm{kgf} / \mathrm{cm}^{2}\right)$ pode ser justificada pelas características das fibras musculares que constituem os mesmos, uma vez que o músculo triceps brachii teve, para todos os tipos de fibras musculares identificadas (SO, FOG e FG), maiores áreas e diâmetros do que o músculo longissimus lumborum, originando carne mais texturizada e com a superfície menos lisa (Leão, 2008). Os resultados deste estudo corroboram os achados de Oliveira et al. (2004), que avaliaram a maciez da carne ovina e também constataram que, em cordeiros, o músculo longissimus dorsi foi mais macio que o triceps brachii, com valores de $2,73 \mathrm{e} 3,77 \mathrm{kgf} / \mathrm{cm}^{2}$.

Houve efeito $(\mathrm{P}<0,05)$ da interação volumoso $\times$ relação volumoso:concentrado sobre o teor de escatol da gordura dos cordeiros confinados (Tabela 7). O escatol (3-metilindole) é um composto volátil derivado da fermentação microbiana do aminoácido triptofano no rúmen (Deslandes et al., 2001; Jensen, 2006). Segundo Young et al. (1997), o sabor característico da carne ovina está fortemente correlacionado à sua presença na gordura.

Apesar da diferença ocasionada pelas dietas, esses valores são considerados muito baixos. Isto pode ter ocorrido porque, quando os animais são criados em pasto e terminados em confinamento, passando a receber dietas com concentrado, depois de apenas duas semanas de fornecimento da nova dieta, a concentração de escatol nos tecidos reduz significativamente (Vasta \& Priolo, 2006).

Tabela 7 - Teor de escatol ( $\mu \mathrm{g} / \mathrm{g}$ de gordura) da gordura subcutânea do músculo longissimus lumborum de cordeiros terminados em confinamento com dietas contendo silagem de milho (SM) ou cana-de-açúcar (CA) e dois níveis de concentrado

\begin{tabular}{lccc}
\hline Variável & Volumoso & \multicolumn{2}{c}{ Relação volumoso:concentrado } \\
\cline { 3 - 4 } & & $60: 40$ & $40: 60$ \\
\hline Escatol & $\mathrm{SM}$ & $0,79 \mathrm{Aa}$ & $0,45 \mathrm{Bb}$ \\
& $\mathrm{CA}$ & $0,38 \mathrm{Bb}$ & $0,80 \mathrm{Aa}$ \\
\hline
\end{tabular}

Médias seguidas pela mesma letra maiúscula na linha e mesma letra minúscula na coluna não diferem $(\mathrm{P}>0,05)$ pelo teste Tukey.
Priolo et al. (2001) citaram que a carne de ovinos criados em sistemas mais extensivos de produção apresentaram maior concentração de escatol em comparação à dos animais terminados com concentrados. Young et al. (2003), ao avaliarem o efeito da dieta sobre a concentração de escatol na gordura de cordeiros Romney abatidos aos 132 ou 232 dias, verificaram que, aos 132 dias, a dos cordeiros criados em pasto tiveram altas concentrações $(41 \mathrm{ng} / \mathrm{g}$ ) em comparação à dos animais que receberam alfafa e milho $(3,5$ e 9,0 ng/g, respectivamente), no entanto, aos 232 dias, pouca diferença foi verificada.

A interação volumoso $\times$ relação volumoso:concentrado teve efeito $(\mathrm{P}<0,05)$ sobre as características sensoriais da carne dos cordeiros (Tabelas 8 e 9). Para o lombo e a paleta dos cordeiros alimentados com cana-de-açúcar e maior quantidade de concentrado (60\%), foram atribuídas as maiores notas e as maiores pontuações para todos os parâmetros sensoriais avaliados (sabor, textura, preferência e aceitação).

Madruga et al. (2005) também observaram que a alimentação afetou as características sensoriais da carne de

Tabela 8 - Análise sensorial do lombo de cordeiros terminados em confinamento com dietas contendo silagem de milho (SM) ou cana-de-açúcar (CA) e dois níveis de concentrado

\begin{tabular}{lccc}
\hline Variável & Volumoso & \multicolumn{2}{c}{ Relação volumoso:concentrado } \\
\cline { 3 - 4 } & & $60: 40$ & $40: 60$ \\
\hline \multirow{2}{*}{ Sabor } & SM & $7,53 \mathrm{a}$ & $7,20 \mathrm{~b}$ \\
\multirow{2}{*}{ Textura } & CA & $7,73 \mathrm{a}$ & $8,07 \mathrm{a}$ \\
\multirow{2}{*}{ Preferência } & SM & $7,60 \mathrm{a}$ & $7,33 \mathrm{~b}$ \\
& CA & $8,13 \mathrm{a}$ & $8,53 \mathrm{a}$ \\
\multirow{2}{*}{ Aceitação } & SM & $7,13 \mathrm{a}$ & $7,27 \mathrm{~b}$ \\
& $\mathrm{CA}$ & $7,67 \mathrm{a}$ & $8,20 \mathrm{a}$ \\
& $\mathrm{SM}$ & $7,33 \mathrm{a}$ & $7,27 \mathrm{~b}$ \\
& $\mathrm{CA}$ & $7,93 \mathrm{a}$ & $8,33 \mathrm{a}$ \\
\hline
\end{tabular}

Médias seguidas pela mesma letra minúscula na coluna não diferem $(\mathrm{P}>0,05)$ pelo teste não-paramétrico de Wilcoxon.

Tabela 9 - Análise sensorial da paleta de cordeiros terminados em confinamento com dietas contendo silagem de milho (SM) ou cana-de-açúcar (CA) e dois níveis de concentrado

\begin{tabular}{lccc}
\hline Variável & Volumoso & \multicolumn{2}{c}{ Relação volumoso:concentrado } \\
\cline { 3 - 4 } & & $60: 40$ & $40: 60$ \\
\hline Sabor & SM & $8,13 \mathrm{Aa}$ & $7,40 \mathrm{Bb}$ \\
\multirow{2}{*}{ Textura } & CA & $8,06 \mathrm{Aa}$ & $8,26 \mathrm{Aa}$ \\
\multirow{2}{*}{ Preferência } & SM & $8,06 \mathrm{Aa}$ & $7,93 \mathrm{Ab}$ \\
& $\mathrm{CA}$ & $8,13 \mathrm{Aa}$ & $8,53 \mathrm{Aa}$ \\
\multirow{2}{*}{ Aceitação } & SM & $8,06 \mathrm{Aa}$ & $7,60 \mathrm{Ab}$ \\
& $\mathrm{CA}$ & $8,13 \mathrm{Aa}$ & $8,46 \mathrm{Aa}$ \\
& $\mathrm{SM}$ & $8,00 \mathrm{Aa}$ & $7,46 \mathrm{Ab}$ \\
& $\mathrm{CA}$ & $8,13 \mathrm{Aa}$ & $8,26 \mathrm{Aa}$ \\
\hline
\end{tabular}

Médias seguidas pela mesma letra maiúscula na linha e mesma letra minúscula na coluna não diferem $(\mathrm{P}>0,05)$ pelo teste não-paramétrico de Wilcoxon. 
cordeiros Santa Inês, de modo que a carne daqueles animais alimentados com palma forrageira foram atribuídas menores notas de textura, maciez, sabor, suculência e aparência. Sañudo et al. (1996) avaliaram as características sensoriais da carne de cordeiros da raça Rasa Aragonesa terminados em confinamento e obtiveram notas de 6,$62 ; 6,67 ; 6,83$ e 6,60 para textura, suculência, sabor e satisfação. Vale ressaltar que neste estudo, apesar do efeito favorável da cana-de-açúcar associado à maior quantidade de concentrado da dieta, as notas atribuídas pelos provadores indicam que as carnes dos cordeiros tiveram boa aceitação.

\section{Conclusões}

A cana-de-açúcar na alimentação de cordeiros confinados não interfere negativamente nas características físico-químicas da carne, mantendo sua qualidade, e por isso pode ser utilizada nesta fase de produção. A cana-deaçúcar associada à maior quantidade de concentrado na dieta de cordeiros confinados imprime maior qualidade sensorial à carne ovina.

\section{Agradecimento}

À Fundação de Amparo à Pesquisa do Estado de São Paulo (FAPESP), pelo apoio financeiro a esta pesquisa.

\section{Referências}

ARCHIMÈDE, H.; PELLONDE, P.; DESPOIS, P. et al. Growth performances and carcass traits of Ovin Martinik lambs fed various ratios of tropical forage to concentrate under intensive conditions. Small Ruminant Research, v.75, n.2-3, p.162-170, 2008 .

BARROS, N.N. Acabamento de cordeiros em confinamento. Disponível em: <http://www.cnpc.embrapa.br/confinamento.htm>. Acesso em: 23 jun. 2004.

CAÑEQUE, V.; SAÑUDO, C. Metodologia para el estúdio de la calidad de la canal y de la carne en rumiantes. Madrid: Instituto Nacional de Investigación y Tecnologia y Alimenticia, 2000. 255p.

CARVALHO, P.R.N.; COLLINS, C.A.; RODRIGUEZ-AMAYA, D.B. Comparison of provitamin A determination by normal-phase gravity-flow chromatography and reversed phase high performance liquid chromatography. Chromatographia, v.33, p.133-137, 1992.

CEZAR, M.F.; SOUSA, W.H. Carcaças ovinas e caprinas: obtenção, avaliação e classificação. Uberaba: Agropecuária Tropical, 2007. 232p.

CIRIA, J.; ASENJO, B. Factores a considerar en el presacrificio y postsacrificio. In: CAÑEQUE, V.; SAÑUDO, C. Metodología para el estudio de la calidad de la canal y de la carne en rumiantes. Madrid: Instituto Nacional de Investigación y Tecnología Agraria y Alimentaria, 2000. p.19-45.

DEVINE, C.E.; GRAAFHUIS, A.E.; MUIR, P.D. et al. The effect of growth rate and ultimate $\mathrm{pH}$ on meat quality of lambs. Meat Science, v.35, n.1, p.63-77, 1993.
DÍAZ, M.T.; VELASCO, S.; CAÑEQUE, V. et al. Use of concentrate or pasture for fattening lambs and its effect on carcass and meat quality. Small Ruminant Research, v.43, n.3, p.257-268, 2002.

FERNANDES, A.R.M.; SAMPAIO, A.A.M.; HENRIQUE, W. et al. Características da carcaça e da carne de bovinos sob diferentes dietas, em confinamento. Arquivo Brasileiro de Medicina Veterinária e Zootecnia, v.60, n.1, p.139-147, 2008.

FERNANDES, A.R.M.; SAMPAIO, A.A.M.; HENRIQUE, W. et al. Composição em ácidos graxos e qualidade da carne de tourinhos Nelore e Canchim alimentados com dietas à base de cana-deaçúcar e dois níveis de concentrado. Revista Brasileira de Zootecnia, v.38, n.2, p.328-337, 2009.

GARCIA-REGUEIRO, J.A.; DIAZ, I. Evaluation of the contribution of skatole, indole, androstenone and androstenols to boar-taint in back fat of pigs by HPLC and capillary gas chromatography (CGC). Meat Science, v.25, p.307-316, 1989.

GARRIDO, M.D.; BAÑÓN, S. Medida del pH. In: CAÑEQUE, V.; SAÑUDO, C. Metodología para el estudio de la calidad de la canal y de la carne en rumiantes. Madrid: Instituto Nacional de Investigación y Tecnología Agraria y Alimentaria, 2000. p.145-155.

KNIGHT, T.W.; DEATH, A.F.; MUIR, P.D. et al. Effect of dietary vitamin A on plasma and liver carotenoid concentrations and fat colour in Angus and Angus crossbred cattle. New Zealand Journal of Agricultural Research, v.39, n.2, p.281-292, 1996.

LEÃO, A.G. Qualidade da carne de cordeiros terminados com dietas contendo cana-de-açúcar ou silagem de milho. 2008. 117f. Tese (Doutorado em Zootecnia) - Faculdade de Ciências Agrárias e Veterinárias, Universidade Estadual Paulista, Jaboticabal.

LEÃO, A.G.; SILVA SOBRINHO, A.G.; MORENO, G.M.B. et al Características nutricionais da carne de cordeiros terminados com dietas contendo cana-de-açúcar ou silagem de milho e dois níveis de concentrado. Revista Brasileira de Zootecnia, v.40, n.5, p.1072-1079, 2011.

LYON, C.E.; LYON, B.G.; DICKENS, J.A. Effects of carcass stimulation, deboning time, and marination on color and texture of broiler breast meat. Journal of Applied Poultry Research, v.7, n.1, p.53-60, 1998.

LYON, D.H.; FRANCOMBE, M.A.; HASDELL, T.A. et al Guidelines for sensory analysis in food product development and quality control. London: Chapman \& Hall, 1992. $131 \mathrm{p}$.

MADRUGA, M.S.; SOUSA, W.H.; ROSALES, M.D. et al. Qualidade da carne de cordeiros Santa Inês terminados com diferentes dietas. Revista Brasileira de Zootecnia, v.34, n.1, p.309-315, 2005.

MADRUGA, M.S.; GALVÃO, M.S.; COSTA, R.G. et al. Perfil aromático e qualidade química da carne de caprinos Saanen alimentados com diferentes níveis de concentrado. Revista Brasileira de Zootecnia, v.37, n.5, p.936-943, 2008.

MOLENTO, M.B.; TASCA, C.; GALLO, A. et al. Método Famacha como parâmetro clínico individual de infecção por Haemonchus contortus em pequenos ruminantes. Ciência Rural, v.34, n.4, p.1139-1145, 2004

MORENO, G.M.B.; SILVA SOBRINHO, A.G.; LEÃO, A.G. Rendimentos de carcaça, composição tecidual e musculosidade da perna de cordeiros alimentados com silagem de milho ou cana-de-açúcar em dois níveis de concentrado. Arquivo Brasileiro de Medicina Veterinária e Zootecnia, v.62, n.3, p.686-695, 2010.

MURRAY, A.C. The evaluation of muscle quality. In: JONES, S.D.M (Ed.) Quality and grading of carcasses of meat animals. New York: CRC Press, 1995. p.83-107.

NATIONAL RESEARCH COUNCIL - NRC. Nutrient requirements of sheep. New York: National Academy Press, 1985. 99p.

OLIVEIRA, I.; SILVA, T.J.P.; FREITAS, M.Q. et al. Caracterização do processo de rigor mortis em músculos de cordeiros e carneiros 
da raça Santa Inês e maciez da carne. Acta Scientiae Veterinariae, v.32, n.1, p.25-31, 2004.

OSÓRIO, M.T.M.; OSÓRIO, J.C.S.; SILVA SOBRINHO, A.G. Avaliação instrumental da carne ovina. In: SILVA SOBRINHO, A.G.; SAÑUDO, C.A.; OSÓRIO, J.C.S. et al. (Eds.) Produção de carne ovina. Jaboticabal: Funep, 2008. p.353-365.

PERLO, F.; BONATO, P.; TEIRA, G. et al. Meat quality of lambs produced in the Mesopotamia region of Argentina finished on different diets. Meat Science, v.79, n.3, p.576-581, 2008.

PRACHE, S.; PRIOLO, A.; GROLIER, P. Persistence of carotenoid pigments in the blood of concentrate-finished grazing sheep: its significance for the traceability of grass-feeding. Journal of Animal Science, v.81, n.2, p.360-367, $2003 \mathrm{a}$.

PRACHE, S.; PRIOLO, A.; GROLIER, P. Effect of concentrate finishing on the carotenoid content of perirenal fat in grazing sheep: its significance for discriminating grass-fed, concentratefed and concentrate-finished grazing lambs. Animal Science, v.77, n.2, p.225-233, 2003b.

PRACHE, S.; THERIEZ, M. Traceability of lamb production systems: carotenoids in plasma and adipose tissue. Animal Science, v.69, n.1, p.29-36, 1999

PRIOLO, A.; MICOL, D.; AGABRIEL, J. Effects of grass feeding systems on ruminant meat colour and flavour. A review. Animal Research, v.50, p.185-200, 2001

PRIOLO, A.; MICOL, D.; AGABRIEL, J. et al. Effect of grass or concentrate feeding systems on lamb carcass and meat quality. Meat Science, v.62, n.2, p.179-185, 2002.

RAMOS, E.M.; GOMIDE, L.A.M. Avaliação da qualidade de carnes: fundamentos e metodologias. 5.ed. Viçosa, MG: UFV, 2007. 599p.

RIBEIRO, E.L.A.; OLIVEIRA, H.C.; CASTRO, F.A.B. et al. Características de carcaça e carne de cordeiros mestiços de três grupos genéticos. Semina: Ciências Agrárias, v.31, n.3, p.793-802, 2010.

SAÑUDO, C.A. La calidad organoléptica de la carne con especial referencia a la especie ovina. Factores que la determinan, métodos de medidas y causas de variación. In: CURSO INTERNACIONAL SOBRE PRODUCCIÓN DE GANADO OVINO, 3., 1991, Zaragoza. Palestras... Zaragoza: 1991. 117p.

SAÑUDO, C.; SANCHEZ, A.; ALFONSO, M. Small ruminant production systems and factors affecting lamb meat quality. Meat Science, v.49, n.1, p.29-64, 1998.

SAÑUDO, C.; SANTOLARIA, M.P.; MARÍA, G. et al. Influence of carcass weight on instrumental and sensory lamb meat quality in intensive production systems. Meat Science, v.42, n.2, p.195-202, 1996.

SAÑUDO, C.A.; DELFA, R.; CASAS, M. Influencia del genótipo en la calidad de la carne del ternasco de Aragón. In: JORNADAS
CIENTÍFICAS DE LA SOCIEDADE ESPÃNOLA DE OVINOTECNIA Y CAPRINOTECNIA, 16., 1992, Pamploma. Anais... Pamploma: SEOC, 1992. p.473-479.

SEN, A.R.; SANTRA, A.; KARIM, S.A. Carcass yield, composition and meat quality attributes of sheep and goat under semiarid conditions. Meat Science, v.66, n.4, p.757-763, 2004.

SILVA SOBRINHO, A.G. Body composition and characteristics of carcass from lambs of different genotypes and ages at slaughter. 1999. 54f. Thesis (PostDoctorate in Sheep Meat Production) - Massey University, Palmerston North.

SILVA SOBRINHO, A.G. Criação de ovinos. 2. ed. Jaboticabal: Funep, 2001. 302p

SILVA SOBRINHO, A.G. Produção de carne ovina com qualidade. In: SIMPÓSIO DE QUALIDADE DA CARNE, 2., 2005, Jaboticabal. Anais... Jaboticabal: Funep, 2005. 25p.

TORRES, R.A.; COSTA, J.L. Uso da cana-de-açúcar na alimentação animal. In: SIMPÓSIO DE FORRAGICULTURA E PASTAGENS, 2., 2001, Lavras. Anais... Lavras: UFLA, 2001. p.1-20.

TSCHIRHART-HOELSCHER, T.E.; BAIRD, B.E.; KING, D.A. et al. Physical, chemical, and histological characteristics of 18 lamb muscles. Meat Science, v.73, n.1, p.48-54, 2006.

VASTA, V.; PRIOLO, A. Ruminant fat volatiles as affected by diet. A review. Meat Science, v.73, p.218-228, 2006.

YAMAMOTO, S.M. Desempenho e características da carcaça e da carne de cordeiros terminados em confinamento com dietas contendo silagens de resíduos de peixes. 2006. $106 \mathrm{f}$ Tese (Doutorado em Zootecnia) - Faculdade de Ciências Agrárias e Veterinárias, Universidade Estadual Paulista, Jaboticabal.

YANG, A.; LARSEN, T.W.; TUME, R.K. Carotenoid and retinal concentrations in serum, adipose tissue and liver and carotenoids transport in sheep, goats and cattle. Australian Journal of Agricultural Research, v.43, n.8, p.1809-1817, 1992.

YOUNG, O.A.; LANE, G.A.; PRIOLO, A. et al. Pastoral and species flavour in lambs raised on pasture, lucerne or maize. Journal of the Science of Food and Agriculture, v.83, p.93-104, 2003.

YOUNG, O.A.; BERDAGUÉ, J.L.; VIALLON, C. et al. Fat-borne volatiles and sheep meat odour. Meat Science, v.45, n.2, p.183-200, 1997.

ZEOLA, N.M.B.L.; SILVA SOBRINHO, A.G.; GONZAGA NETO, S et al. Influência de diferentes níveis de concentrado sobre a qualidade da carne de cordeiros Morada Nova. Revista Portuguesa de Ciências Veterinárias, v.97, n.544, p.175-180, 2002.

ZEOLA, N.M.B.L.; SILVA SOBRINHO, A.G.; MANZI, G.M. Desempenho e características da carcaça de cordeiros submetidos aos modelos de produção orgánico e convencional. Arquivo Brasileiro de Medicina Veterinária e Zootecnia, v.63, n.1, p.180-187, 2011 . 